\title{
Temperature and Anisotropy Induced Micromechanics for Negative Poisson's Ratio h-BN/5050 Al Alloy Composites
}

\author{
Chennakesava Reddy \\ Department of Mechanical Engineering, JNT University Hyderabad, Telangana, India \\ chennakesava@jntuh.ac.in
}

\begin{abstract}
Lightweight aluminium-ceramic nanoparticle reinforced metal matrix nanocomposites offer significant performance benefits over conventional aluminium alloy materials. In recent years, hexagonal boron nitride has drawn a lot of attraction in the files of metal matrix composites. 5050 aluminium alloy has excellent corrosion resistance and formability. The hexagonal boron nitride exhibits anisotropic character at high temperatures. The test hexagonal boron nitride/5050 aluminium alloy nanocomposites were fabricated by the stir casting method containing $10 \mathrm{vol} . \%$ hexagonal boron nitride and $90 \mathrm{vol. \%}$ 5050 aluminium alloy. Micromechanical properties were analysed for the nanocomposites using ANSYS software code. The square RVE cells were used for the numerical analysis. The numerical results were compared with the experimental results on the nanocomposite systems. The exhibition of negative Poisson's ratio of hexagonal boron nitride/5050 aluminium alloy nanocomposites was due to the anisotropic behaviour of hexagonal boron nitride.
\end{abstract}

Keyword- Hexagonal boron nitride, $5050 \mathrm{Al}$ Alloy, Temperature, Anisotropy, Micromechanics

\section{INTRODUCTION}

Stir cast aluminium-based metal matrix composites have been extensively used in many industrial applications for light weight components due to their high strength-to-weight ratio [1], [2]. In recent times, there has been a growing awareness in using metal matrix composites for high temperature applications, exclusively their thermal stability, in aircraft and automobile applications [3] - [5]. As the metal matrix composite absorbs heat energy, its temperature increases resulting into dimensional change [6] - [8]. The dimensional stability depends upon the thermal mismatch between the matrix alloy and the reinforced material [9], [10].

Thermal conductivity of pure metals is higher than that of alloyed metals [11]. 5050-aluminium alloy is well known for its excellent corrosion resistance and formability. However, it is sensitive to high temperatures. Because of excellent thermal stability, boron nitride (BN) ceramics are usually employed for high temperature applications. Among several crystalline forms of BN, the stable one is hexagonal boron nitride (h-BN) due to its layered structure similar to graphite and strong covalent bonds between boron and nitrogen atoms [12]. But its anisotropic behavior when reinforced in 5050-aluminium alloy is not found in literature at high operating temperatures. It is also important to know the resultant influence of thermal mismatch and thermal boundary resistance between 5050-aluminium alloy matrix and h-BN reinforcement on the micromechanical behaviour $\mathrm{H}$ $\mathrm{BN}$ reinforced aluminium alloy composites. Here, the major task arises from the combination of temperature sensitive matrix alloy (5050-aluminium alloy) and anisotropic characteristic of reinforcement (h-BN). To establish the influence of these characteristics of 5050-aluminium alloy and h-BN, the composites of hBN/5050-aluminium alloy are tested at high temperatures. This paper describes the micromechanical behavior subjected to both temperature and tensile loading to investigate thermal stability of h-BN/5050-aluminium alloy composites.

\section{MATERIALS AND Methods}

5050-aluminium (Al) alloy and hexagonal boron nitride were used, respectively, for matrix and reinforcement. ANSYS software was employed for the numerical analysis of RVE (representative volume element) models of h-BN/5050 Al alloy metal matrix nanocomposites. The size and shape of were assumed to be $90 \mathrm{~nm}$ as shown in Fig. 1 and spherical in the present study. The volume fraction of h-BN nanoparticles was 10\%. The existence of an interphase between the h-BN nanoparticle and the $5050 \mathrm{Al}$ alloy matrix was also taken into account for the numerical analysis. The plane strain boundary conditions were imposed on RVE models for the numerical analysis [13]. Prior to carry on numerical analysis, the $5050 \mathrm{Al}$ alloy was tested for unidirectional tensile loading under isothermal temperature conditions. The operating temperatures were $30^{\circ} \mathrm{C}$ (ambient temperature), $100^{\circ} \mathrm{C}$. $200^{\circ} \mathrm{C}$ and $300^{\circ} \mathrm{C}$. The RVE models were numerically tested for the ultimate tensile strength of the $5050 \mathrm{Al}$ alloy at different temperatures. The numerical results were validated with experimentally tested samples of the h-BN/5050 Al alloy nanocomposites. The behaviours h-BN nanoparticle, $5050 \mathrm{Al}$ alloy and interphase were also compared with SEM microstructures. 

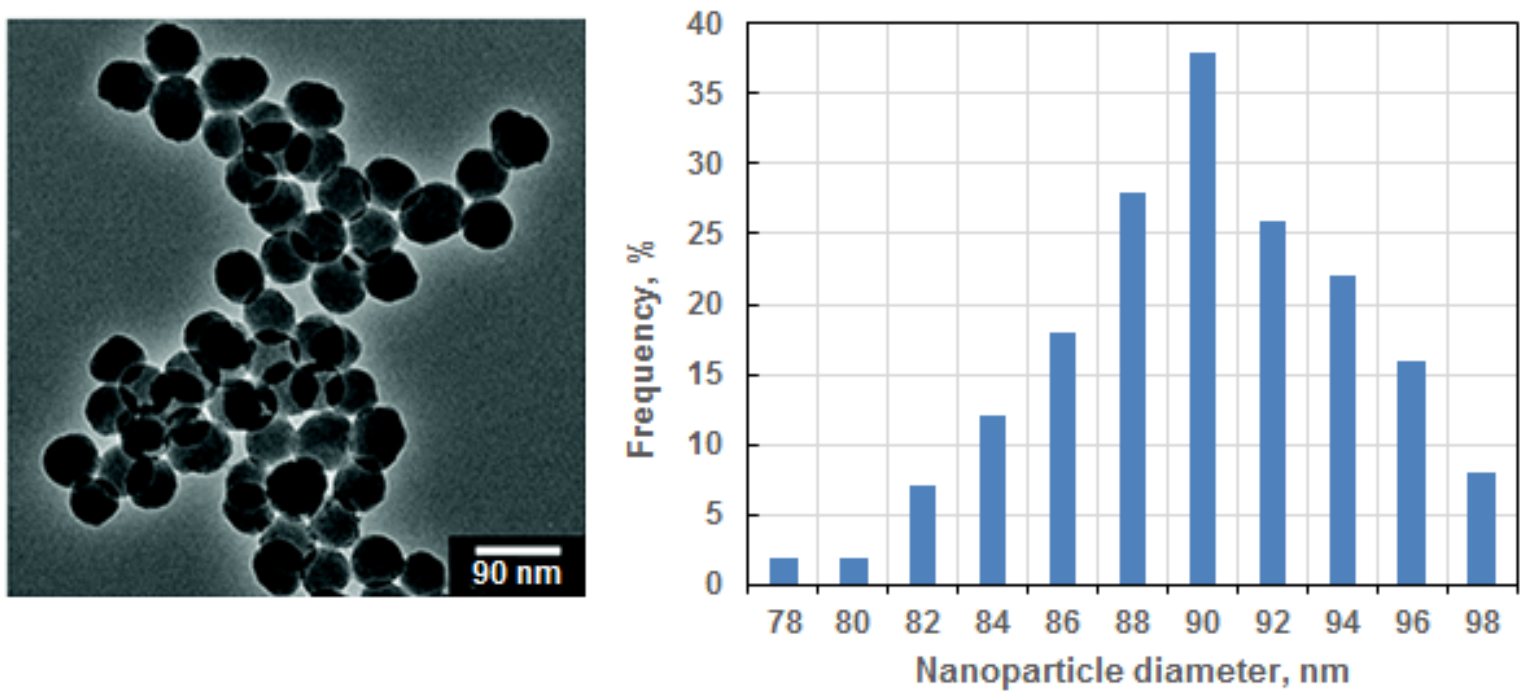

Fig.1. Size distribution of h-BN nanoparticles.

\section{III.RESULTS AND DISCUSSION}

The size distribution of h-BN nanoparticles used in the present work is shown in Fig. 1. The average particle size was $90 \mathrm{~nm}$. Hexagonal boron nitride is composed of boron and nitrogen atoms disposed in a honeycomb lattice as shown in Fig. 2. The effect of temperature on the lattice parameters (a and c) of h-BN is shown in Fig. 3. The relative change of a and c on increasing the temperature in the present study range $\left(30^{\circ} \mathrm{C}\right.$ to $\left.300^{\circ} \mathrm{C}\right)$ is about $-0.062 \%$ and $+0.81 \%$, respectively. The thermal expansion of h-BN along a-direction is negative; and that along the c-direction is positive.

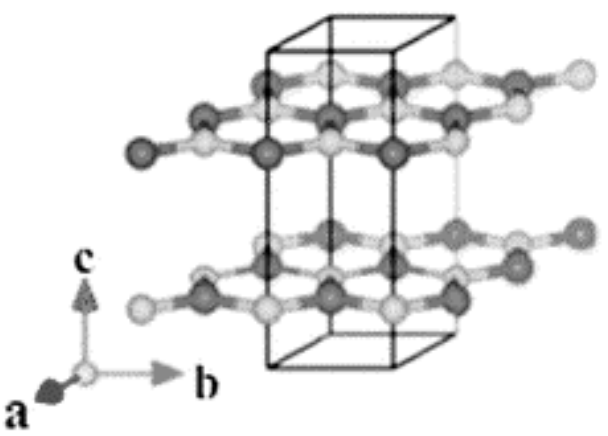

Fig. 2. Hexagonal boron nitride.
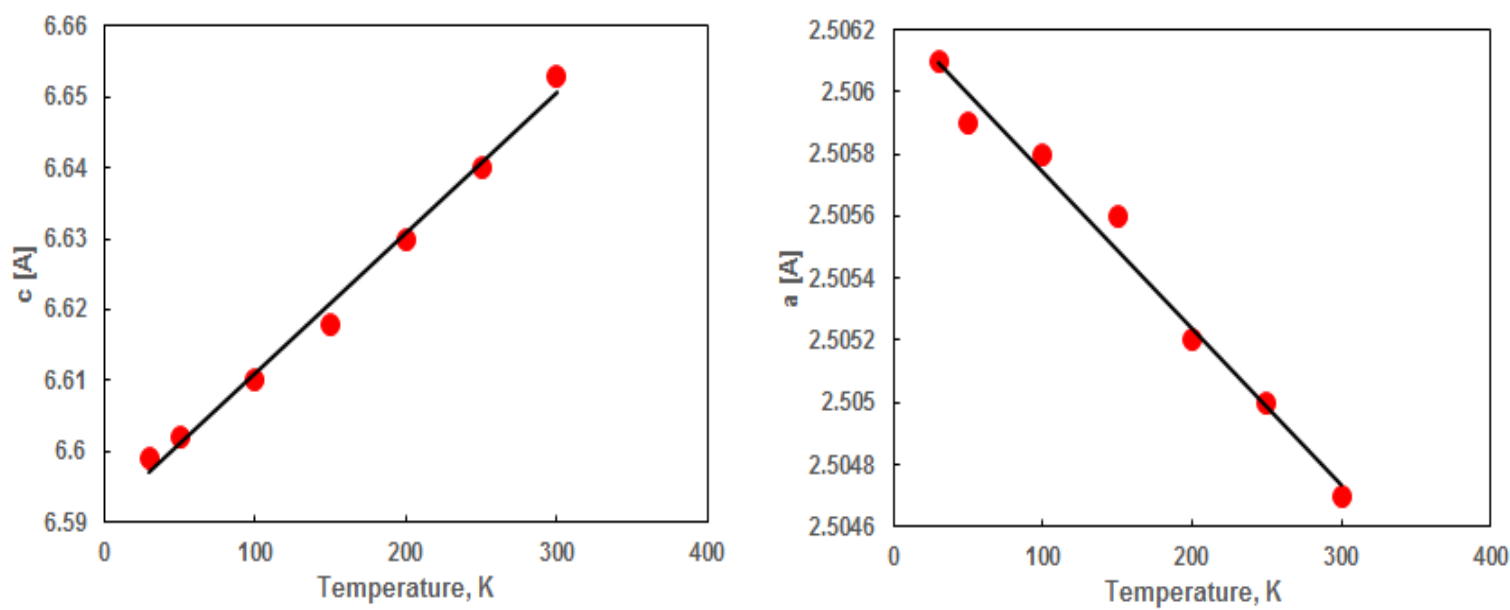

Fig. 3. Thermal expansion of a and c lattice parameters of h-BN.

The effect of temperature on the linear dimension of RVE cell along the loading direction is shown in Fig. 4. It is observed that the dimension along the loading direction increases with increasing temperature of the RVE cell [14], [15]. If observed keenly, the h-BN nanoparticle is slightly affected by the change in temperature while 
the $5050 \mathrm{Al}$ alloy matrix has elongated largely along the loading direction. When heated the RVE cell to $300^{\circ} \mathrm{C}$, a sudden drop is noticed at the interface between h-BN nanoparticle and $5050 \mathrm{Al}$ alloy matrix. This seems to be debonding of the matrix with the reinforcement.
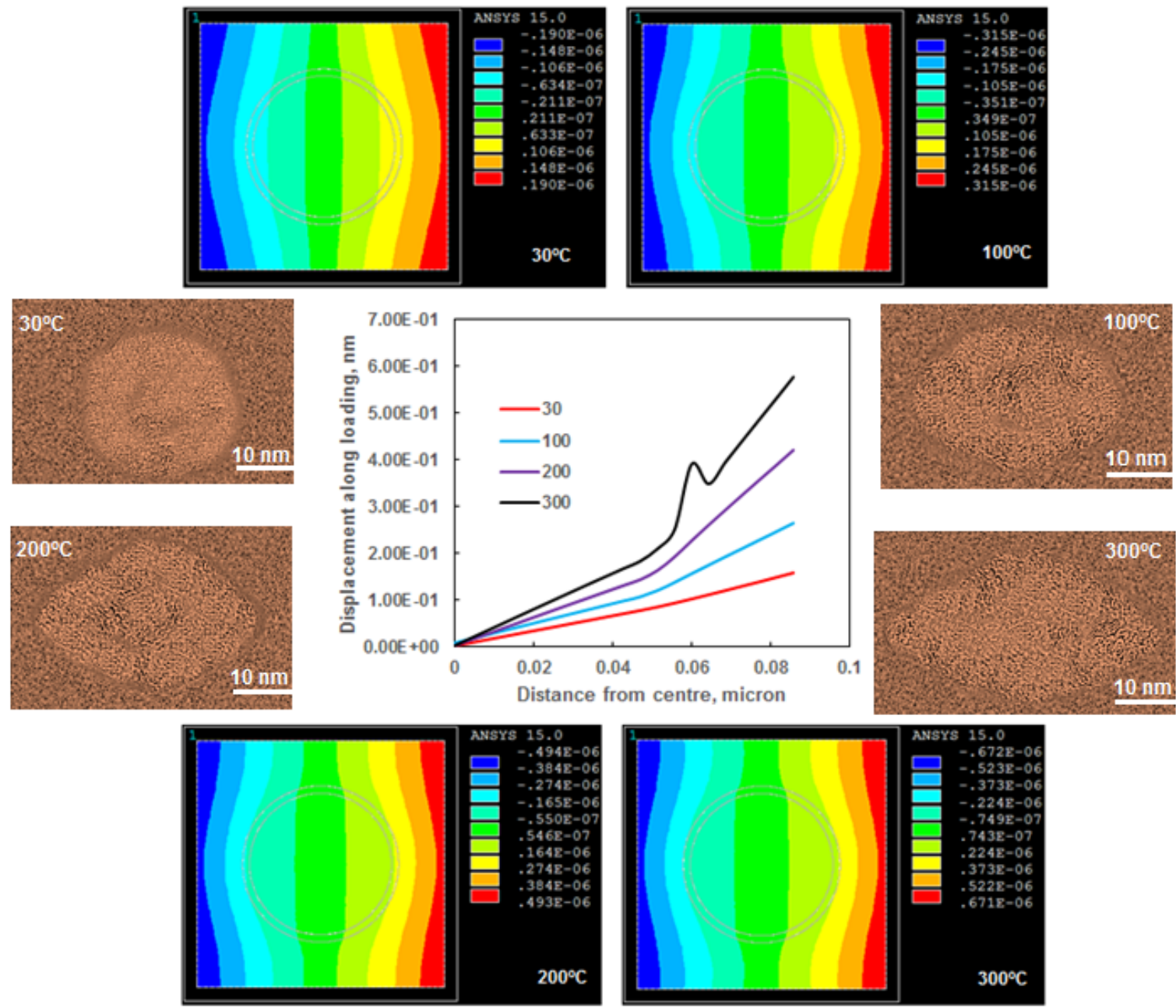

Fig. 4. Effect of temperature on deformation behavior of h-BN/5050 $\mathrm{Al}$ alloy nanocomposites.

The influence of temperature on strains and stresses induced parallel and perpendicular to loading direction is shown in Fig. 5. The strain increases with an increase in the temperature in the regions of the $5050 \mathrm{Al}$ alloy matrix in the directions parallel and normal to the loading as shown in Fig. 5(a). The strains are tensile in the parallel direction of tensile loading, while they are compressive in the normal direction of loading. The strain induced in the h-BN nanoparticle increases with the raise in temperature along parallel and perpendicular directions of the applied tensile load. The increase in strain along the perpendicular direction in the h-BN nanoparticle is very interesting phenomena. For the temperature below $100^{\circ} \mathrm{C}$ the strains are compressive in the h-BN nanoparticle; whereas above $200^{\circ} \mathrm{C}$ the strains are tensile. This phenomenon may influence the Poisson's ratio of the h-BN nanoparticle. For the operation temperatures, $30^{\circ} \mathrm{C}$ and $100^{\circ} \mathrm{C}$, the h-BN nanoparticle has behaved with positive Poisson's ratio, whereas it has with negative Poisson's ration for the operation temperatures $200^{\circ} \mathrm{C}$ and $300^{\circ} \mathrm{C}$ as shown in Fig. 6. This may be due to anisotropic behavior of h.BN nanoparticles. Poisson's ratio is to be positive, most materials become thinner in cross-section when pulled due to realign of inter-atomic bonds after deformation. If material expands laterally when stretched, the Poisson's ratio becomes negative. As mentioned in [16], the anisotropic materials with matrix elastic constants have some negative Poisson's ratio. Such materials have some hidden variables viz., the complete set of tensorial, stressstrain and state variable. Also, in another article [17], it was stated that Poisson's ratio in materials is governed by some aspects of the microstructure such as the presence of rotational degrees of freedom, non-affine deformation kinematics, or anisotropic structure. 

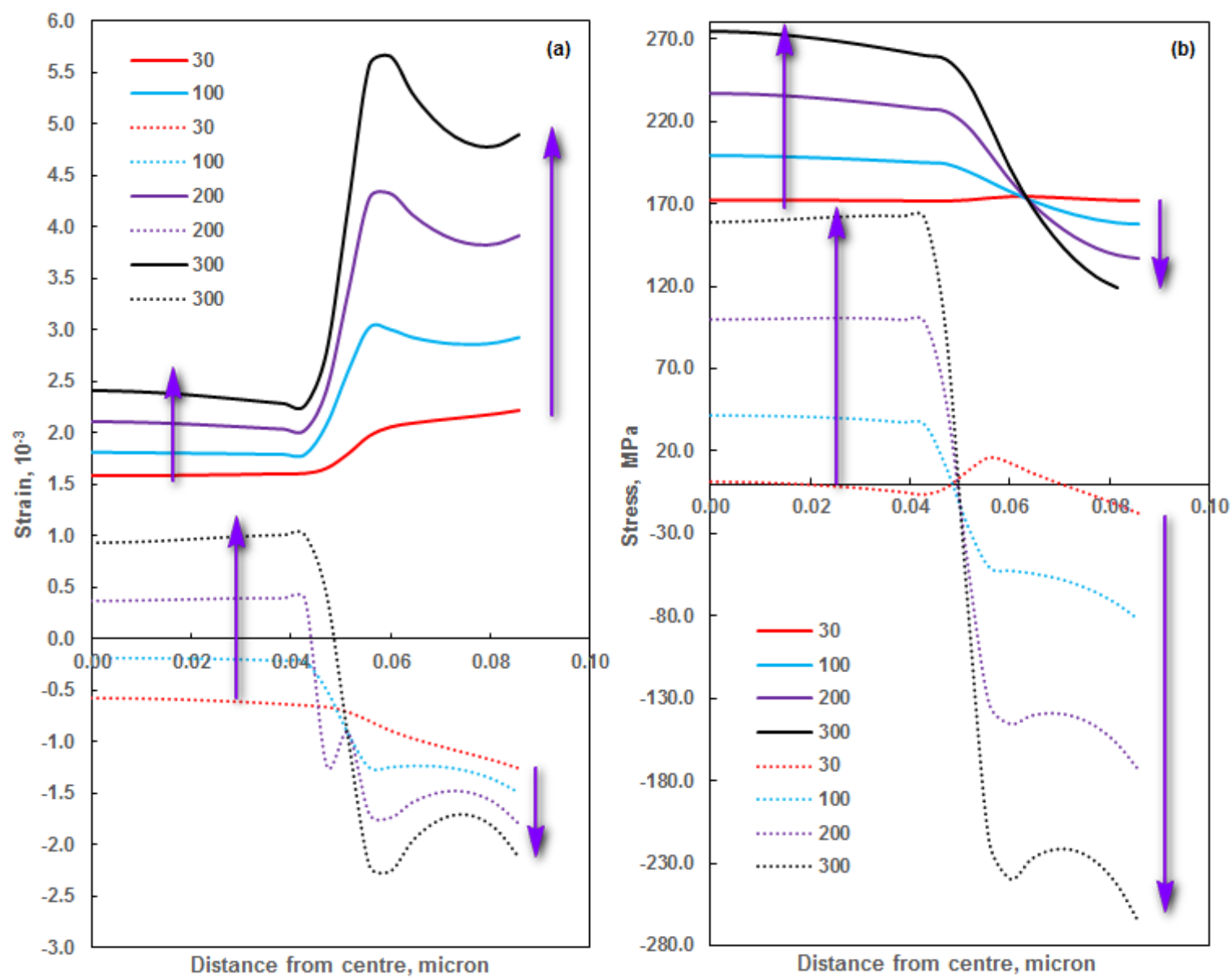

Fig. 5. Effect of temperature on strains and stresses induced in h-BN/5050 Al alloy nanocomposites: solid lines represent along load direction and dotted lines correspond to normal direction to loading.

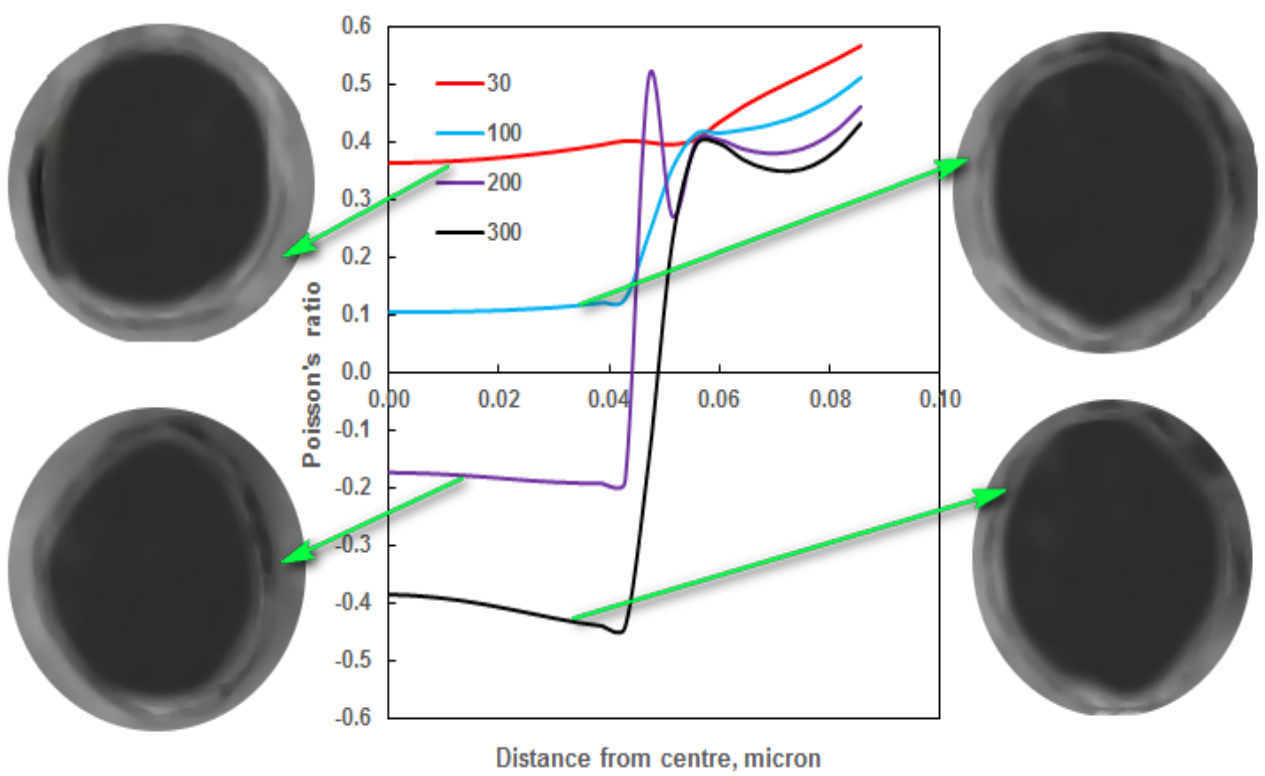

Fig. 6. Effect of temperature on Poisson's ratio h-BN/5050 Al alloy nanocomposites.

The stresses induced in the h-BN increase with increase in the temperature [18]. The tensile stresses induced in the matrix material along the loading direction decrease with increase in the temperature as shown in Fig. 5(b), but interestingly the compressive stresses increase with in the temperature. This is due to the expansion of the h$\mathrm{BN}$ nanoparticle along the normal direction of loading resulting the compression of the matrix material. The raster images of stresses obtain from ANSYS software code are illustrated in Fig. 7 and 8 . The h-BN nanoparticle and the interphase experience higher stresses along either parallel (Fig. 7) or normal directions (Fig. 
8) of loading than the $5050 \mathrm{Al}$ alloy matrix. This indicates the transfer of load from the matrix material to the nanoparticle vis the interphase. As the temperature increases the interphase experiences more and more stress leading decohesion or fracture.
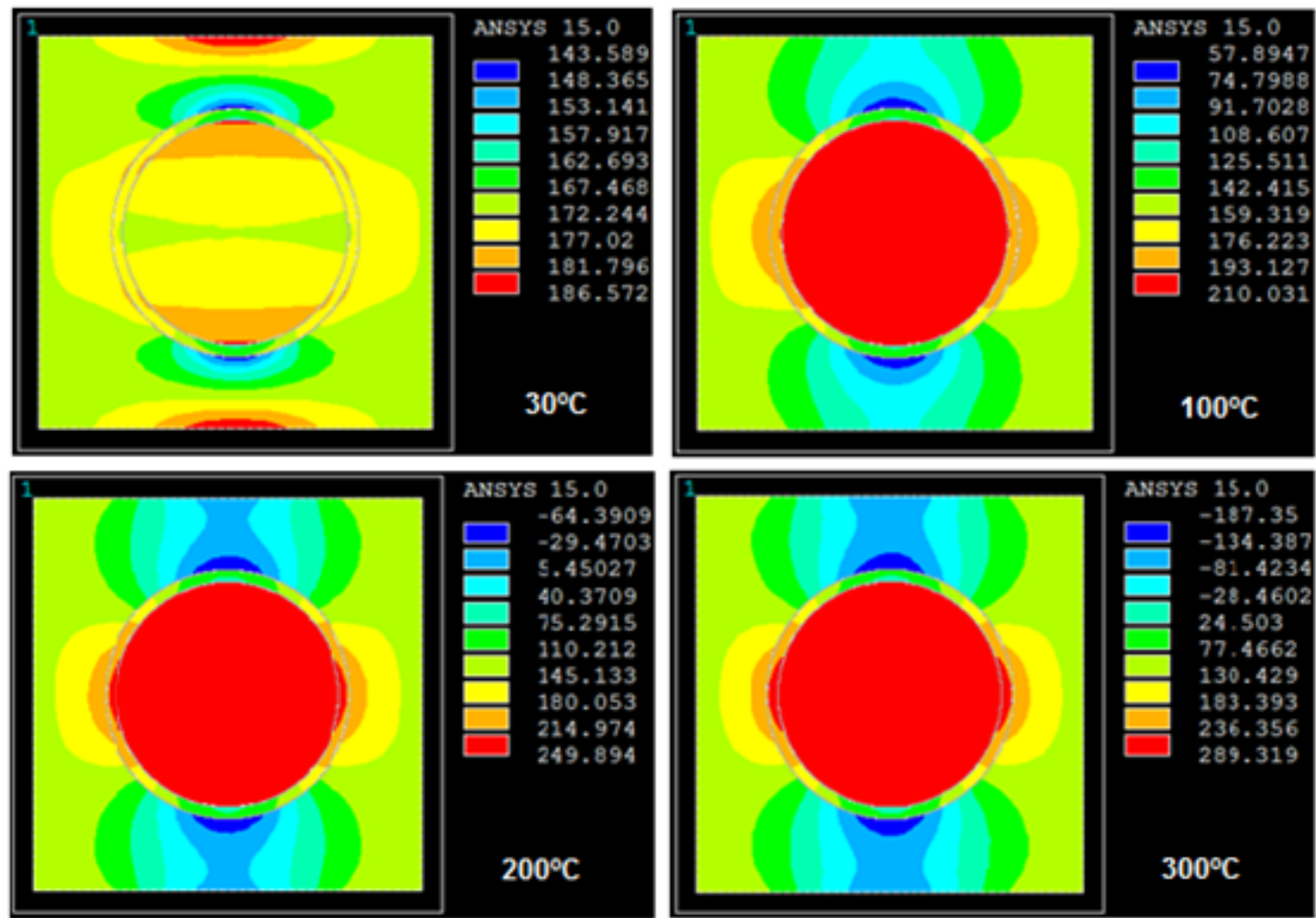

Fig. 7. Stresses induced along load direction
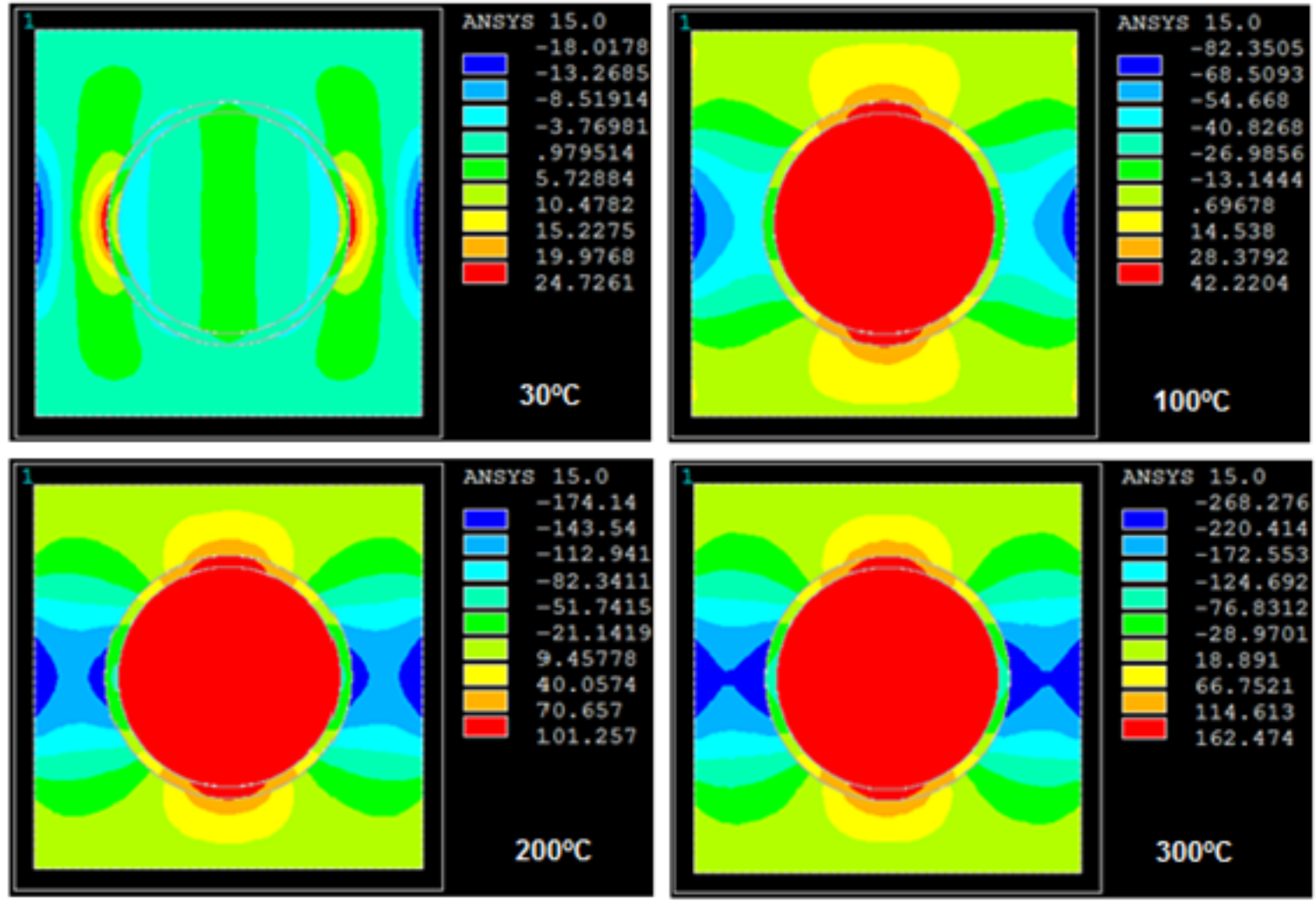

Fig. 8. Stresses induced along normal to load direction. 
Fig. 9 reveal he stress intensity values developed in the RVE cells. The stress intensity values in their ascending order are for interphase, matrix (5050 Al alloy) and reinforcement (h-BN nanoparticle). Below $100^{\circ} \mathrm{C}$ neither the matrix nor the interphase have experienced plastic deformation leading to their fracture. Above $200^{\circ} \mathrm{C}$ both the matrix and the interphase have experience severe plastic deformation leading to their fracture. From the raster images observed from Fig. 10 the stress intensity is noticed at the interphase only. The stress intensity increases along the periphery of h-BN nanoparticle as the temperature of h-BN/5050 Al alloy nanocomposite increased. In nanoparticle reinforced metal matrix composites, the separation of nanoparticles from the matrix material increases with deformation [19], which in turn increases with temperature, and influences the overall stress-strain behaviour of the nanocomposite [8]. In another work [20], it was stated that with an increase in stress intensity, the debonding damage spreads out, and the damaged zone is established ahead of the crack tip.

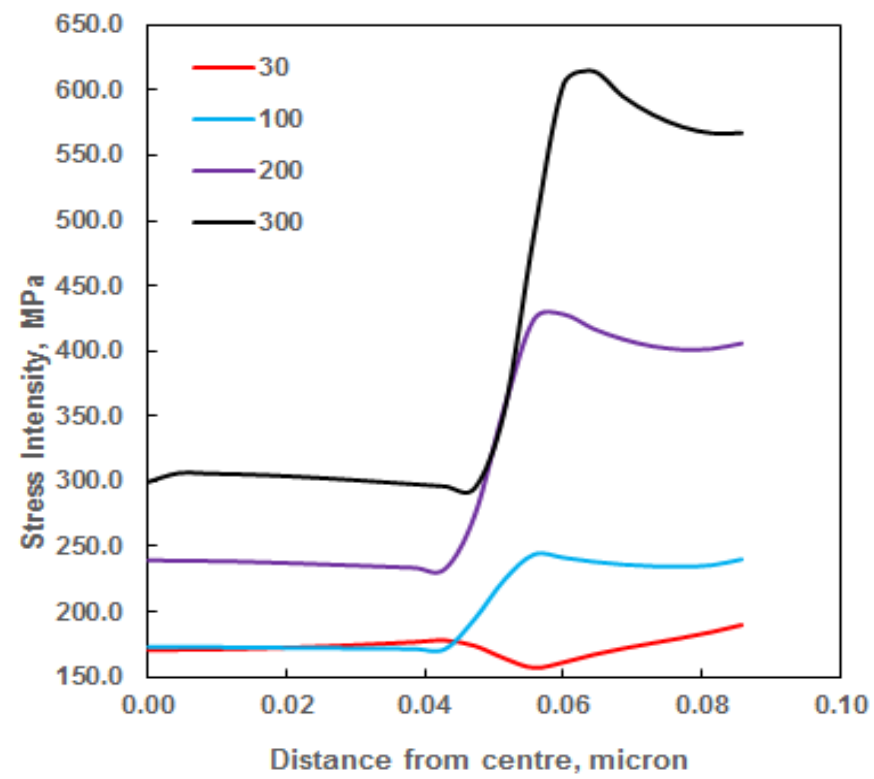

Fig. 9. Stresses intensity in h-BN/5050 Al alloy nanocomposite.
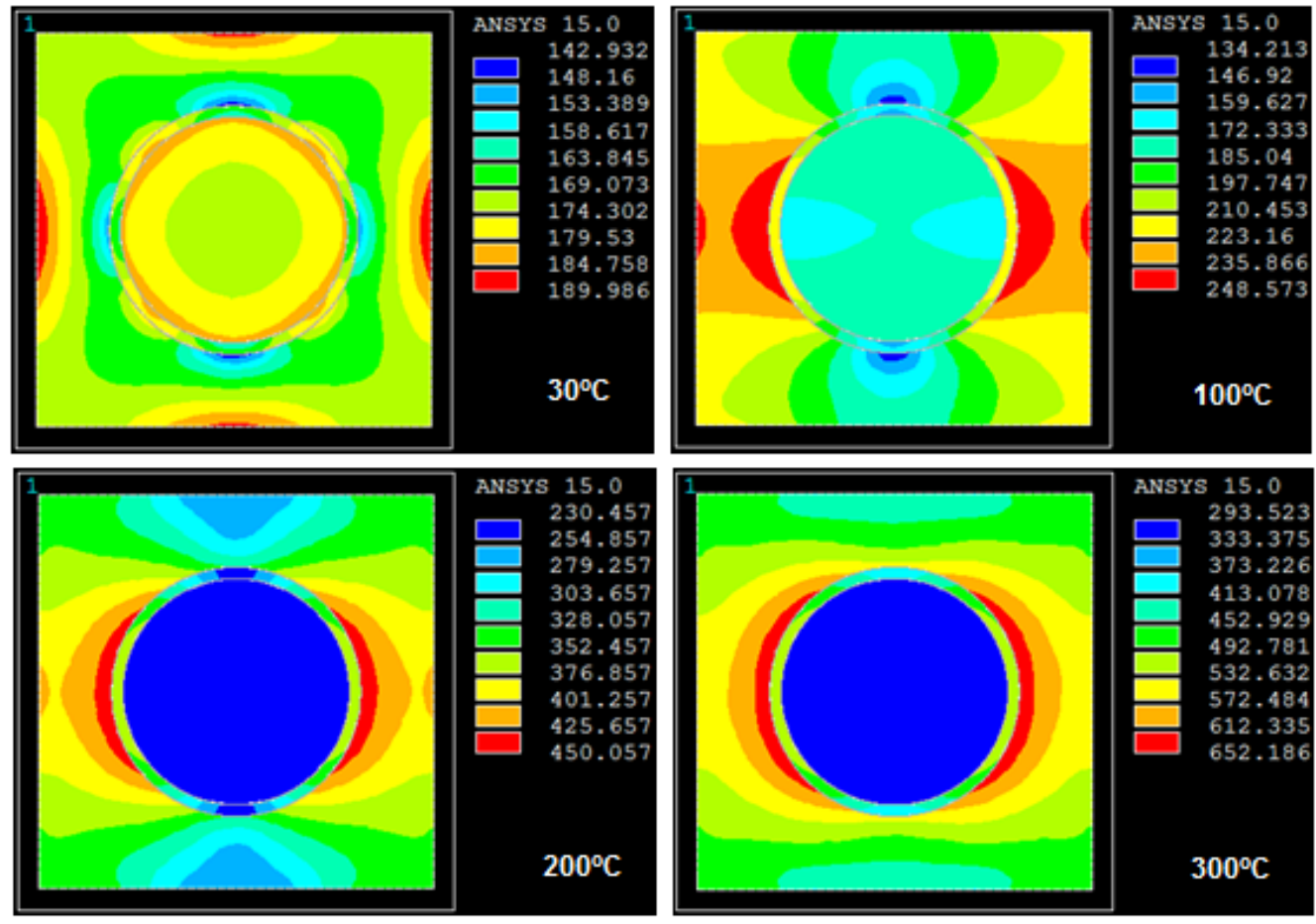

Fig. 10. Raster images of stresses intensity in h-BN/5050 Al alloy nanocomposite. 
Fig. 11 represents the influence of temperature on the modulus of elasticity of h-BN/5050 Al alloy nanocomposites. The tensile modulus (along loading direction) of h-BN nanoparticle is not influenced by the temperature. It is nearly constant at all temperatures. Below $100^{\circ} \mathrm{C}$, the modulus of elasticity (along normal to loading) in the h-BN nanoparticle is compressive, whereas it is tensile above $200^{\circ} \mathrm{C}$ due to negative Poisson's ratio and anisotropic behavior of h-BN as seen from Fig. 8. For the matrix material (5050 Al alloy), the tensile modulus of elasticity (along loading direction) decreases with increases in the temperature. There is drastic fall of stiffness (modulus of elasticity) of the interphase with raise in the temperature. Also, this supports the fracture of interphase at high operating temperatures.

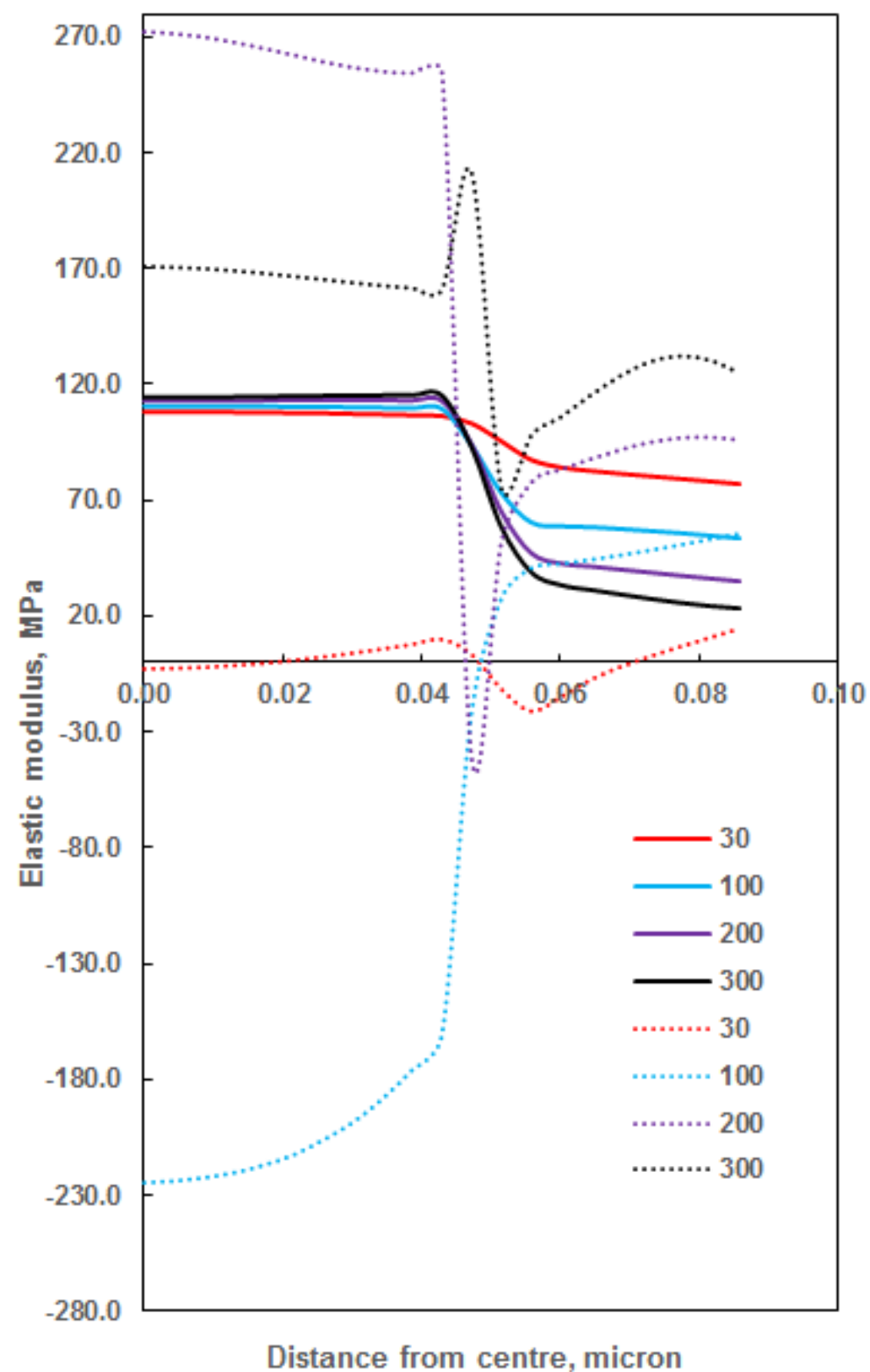

Fig. 11. Modulus of elasticity of h-BN/5050 Al alloy nanocomposite; solid lines represent along load direction and dotted lines correspond to normal direction to loading.

\section{IV.CONCLUSION}

The temperature and anisotropy induced micromechanics of h-BN/5050 Al alloy have been investigated numerically and experimentally. The critical conclusion of this work is that the negative Poisson's ratio is mainly due to the anisotropic behavior of h-BN above $200^{\circ} \mathrm{C}$ operational temperature when subjected to unidirectional tensile loading of h-BN/5050 Al alloy nanocomposites. 


\section{REFERENCES}

[1] M. K. Surappa, “Aluminum Matrix Composite: Challenge and Opportunities,” Sadhanna (India), vol. 28, no. 1\&2, pp. 319-334, 2003.

[2] A. C. Reddy, and E Zitoun, "Matrix al-alloys for alumina particle reinforced metal matrix composites," Indian Foundry Journal, vol. 51, no.1, pp.12-16, 2009.

[3] R. J. Arsenault, and M. Taya, "Metal Matrix Composites, Thermo mechanical Behavior.” Pergamon Press, First Edition, pp. 219-221, 1989.

[4] D. Hashiguchi, A. N. Ashurst, F. C. Grensing., and J. M. Marder, "Aluminum-Beryllium metal matrix composites for Aerospace Applications,” International Symposium on Advanced Materials for Lightweight Structures, ESTEC., 1992

[5] A. C. Reddy, B. Kotiveerchari, P. Rami Reddy, "Saving of Thermal Energy in Air-Gap Insulated Pistons Using Different Composite Materials for Crowns,” International Journal of Scientific \& Engineering Research, vol. 6, no. 3, pp. 71-74, 2015.

[6] S. Aribo, J. A. Omotoyinbo, and D. O. Folorunso, "High Temperature Mechanical Properties of Silicon Carbide Particulate Reinforced Cast Aluminum Alloy Composite," Leonardo Electronic Journal of Practices and Technologies, vol. 18, pp. 9-16, 2011.

[7] A. C. Reddy, and B. Kotiveerchari, "Effect of aging condition on structure and the properties of Al-alloy/SiC composite," International Journal of Engineering and Technology, vol. 2, no. 6, pp. 462-465, 2010.

[8] C. R. Alavala, "Influence of Temperature on Particulate Fracture of AA2024 Alloy/Titanium Oxide nanoparticulate Metal Matrix Composites,” International Journal of Scientific Engineering and Applied Science, vol. 2, no. 4, pp. 1-6, 2016.

[9] C. R. Alavala, "Influence of CTE Mismatch on Debonding and Particulate Damage in AA1100 Alloy/ZrC Nanoparticulate Metal Matrix Composites," International Journal of Innovative Research in Science, Engineering and Technology, vol. 5, no.3, pp. 34893495, 2016.

[10] A. Khalid, and S. Khan, "Evaluation of the Effective Thermal Properties of Aluminum Metal Matrix Composites Reinforced by Ceramic Particles,” International Journal of Current Engineering and Technology, vol. 5, no. 4, pp. 2884-2897, 2015.

[11] M. Ramesh, and T. Karthikeyan, "Physical and Thermal Properties of Quarry Dust Reinforced A356 Metal Matrix Composites. International Journal of Advanced Mechanical Engineering, vol. 4, pp. 277-284, 2014.

[12] C. R. Alavala, "Comparison of Experimental and Theoretical CTE of Al/h-BN Metal Matrix Composites," International Journal of Material Sciences and Technology, vol. 6, no. 1, pp. 13-20, 2016.

[13] A. C. Reddy, "Estimation of Thermoelastic Behavior of Three-phase: AA1100/Ni-Coated Boron Carbide Nanoparticle Metal Matrix Composites,” International Journal of Scientific \& Engineering Research, vol. 6, no. 10, pp. 662-667, 2015.

[14] X. Huang, H. Zhang, Y. Han, W. Wu, and J. Chen, "Hot deformation behavior of 2026 aluminum alloy during compression at elevated temperature,” Materials Science and Engineering A, vol. 527, no. 3, pp. 485-490, 2010.

[15] A. C. Reddy, "Influence of strain rate and temperature on superplastic behavior of sinter forged Al6061/SiC metal matrix composites," International Journal of Engineering Research \& Technology, vol. 4, no. 2, pp. 189-198, 2011.

[16] R. S. Lakes,” Negative Poisson's ratio materials,” Science, vol. 238, p. 551, 1987.

[17] R. S. Lakes, "Deformation mechanisms of negative Poisson's ratio materials: structural aspects,” Journal of Materials Science, vol. 26, pp. 2287-2292, 1991.

[18] C. R. Alavala, "Effect of Thermoelastic Behavior on interfacial debonding and Particulate Fracture in AA1100/TiN Nanoparticulate Metal Matrix Composites,” International Journal of Science and Research, vol. 5, no. 3, pp. 1295-1300, 2016.

[19] A. C. Reddy, "Studies on loading, cracking and clustering of particulates on the strength and stiffness of 7020/SiCp metal matrix composites,” International Journal of Metallurgical \& Materials Science and Engineering, vol. 5, no. 1, pp. 53-66, 2015.

[20] K. Tohgo, N. Suzuki, and H. Ishi, "Influence of damage evolution on a crack-tip field in particulate reinforced composite," Proceeding of the American Society for composites, pp. 185-187, 1994. 